\title{
Biomineralization of selenium nanoparticles by the fungus Phanerochaete chrysosporium
}

\author{
ESPINOSA-ORTIZ E.J. ${ }^{1}$, GERLACH, R. ${ }^{1}$, LENS P. ${ }^{2}$
}

${ }^{1}$ Center for Biofilm Engineering, Montana State University,

Bozemann, MT, USA (erika.espinosaortiz@montana.edu)

${ }^{2}$ UNESCO-IHE, Institute for Water Education, Delft, NL

\section{Background \& purpose}

Selenium (Se) is a metalloid that at trace concentrations is necessary for animal and human life $\left(\sim 40 \mu \mathrm{g} \mathrm{Se} \mathrm{d}^{-1}\right)$, but at high concentrations becomes toxic $\left(\sim 400 \mu \mathrm{g} \mathrm{Se} \mathrm{d}^{-1}\right)$ [1]. Se in the environment is commonly associated with mining, agricultural and some industrial activities. Se is often released as oxyanions, selenate and selenite, bioaccumulates and represents a risk to the environment. We have investigated the use of the white-rot fungus, Phanerochaete chrysosporium, as a potential agent for remediation of Se-polluted waters $[2,3,4]$.

\section{Results}

P. chrysosporium is able to transform selenite (up to 20 $\mathrm{mg} \mathrm{L}^{-1}$ ) into elemental Se nanoparticles when grown in the form of pellets or biofilms (Fig. 1) under semi-acidic conditions. These Se nanoparticles are a stable and less toxic form of Se with added value for industrial applications. This presentation will provide a synthesis of our findings including descriptions of the effects of selenite on fungal growth, activity and biofilm development, characterization of the produced nanoparticles, and potential use of $P$. chrysosporium for treating Se-polluted acidic effluents (e.g. acid mine drainage and acid seeps) $[2,3,4]$. Unpublished and future work focusing based on creating fungal-bacterial cocultures to enhance Se removal efficiencies will also be discussed.

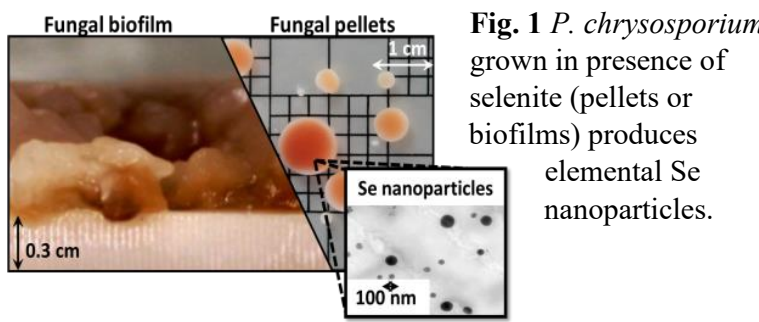

[1] Lenz \& Lens (2009) Sci Total Environ 407(12):36203633. [2] Espinosa-Ortiz et al. (2015) Appl Microbiol Biotechnol 99(5):2405-2418. [3] Espinosa-Ortiz et al. (2016) Bioresource Tenol 210:138-145. [4] Espinosa-Ortiz et al. (2017) Int Biodeter Biodegr 124: 258-266. 